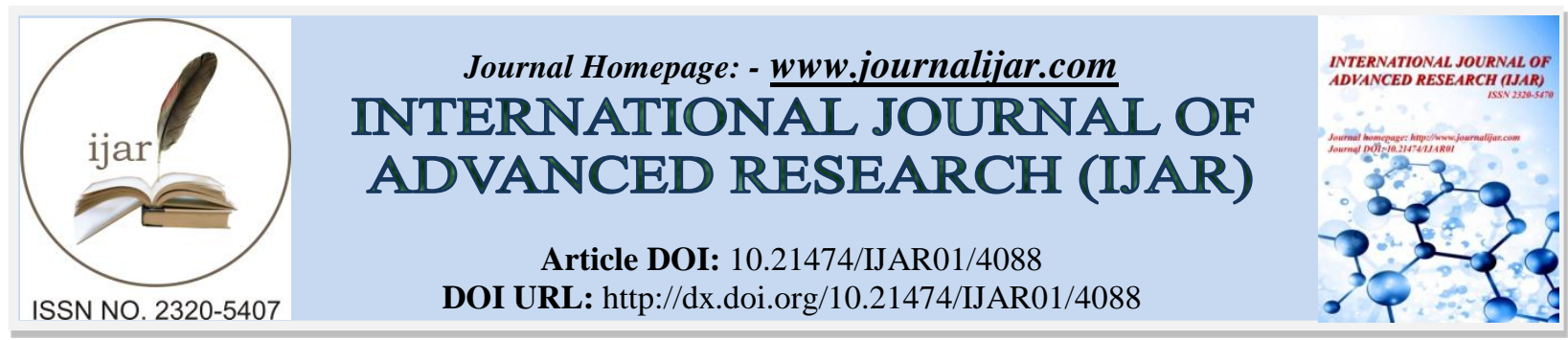

RESEARCH ARTICLE

\title{
A DISCERNMENT STUDY OF STRATEGIC GOALS FOR TALENT ACQUISITION AND METHODS USED TO ASSESS CANDIDATURE.
}

\section{Dr. Rahul Mohare ${ }^{1}$ and Dr. Aniruddha Akarte ${ }^{2}$.}

1. Assistant Professor, Shri Ramdeobaba College of Engineering and Management, Nagpur.

2. Assistant Professor, G H Raisoni Institute of Information Technology, Nagpur.

\section{Manuscript Info}

Manuscript History

Received: 01 March 2017

Final Accepted: 11 April 2017

Published: May 2017

Key words:-

IT Industries, Strategic goals.

\begin{abstract}
Purpose: The purpose of the researcher is to study the perceptions of employees and employers regarding different strategic goals and methods used to assess candidature in talent acquisition adopted by IT industries in Nagpur.

Design/methodology/approach: The entire study is based on the primary data which is collected through the responses from structured questionnaire from the employees and employers of IT industries in Nagpur.

Findings: The research shows that even though there exists correlation between the perception of employee and employer about top strategic goals of talent acquisition they are not significant. As well as correlation so observed between employee and employer's perception about the methods used to assess the candidate in talent acquisition process is significant.

Originality/value: The research will definitely contributes to the understanding of effectiveness and impact of different goals to be set for talent acquisition as well as method used to assess candidature in talent acquisition.

Limitations: The results and their implications come from different respondents of employees and employers of IT organization in Nagpur District only. Results may not be generalizable to other respondents of IT organizations' of other cities.
\end{abstract}

Copy Right, IJAR, 2017,. All rights reserved.

\section{Introduction:-}

In the running decade talent acquisition has been redefined in many different ways and many strategies are reframed accordingly. Talent acquisition has seen great growth in both space and maturity over the last decade. Researcher here wants to study what are the perceptions of employees and employer about the top strategic goals in talent acquisition.

Researcher agrees with Dr. John Sullivan that, not having clearly defined, measurable, and communicated strategic goals can add to the confusion about what is important and what is less important. While having goals provides focus and direction, their absence can cause team members to "wander" and to waste time and resources in lowvalue areas. So if you want your team to be laser focused on the important things, have clear goals that clarify your purpose and that specify what you're trying to accomplish and what great results would look like. 
To contribute more, this paper explores the perception of employee and employers about list of the strategic goals discussed below that truly effective corporate can have.

Reaching many of these recruiting goals is more complicated because the factors involved in reaching them are not 100 percent controlled by either employer or employee. However, it's time for recruiting leaders to learn to follow the standard business practice of assuming "the captain of the ship role" which assumes responsibility for meeting goals that you don't have 100 percent control over.

For this context of study researcher has used the definition of IT industry as industry of the design, development, implementation and management of computer-based information systems, particularly software applications as well as provides services that are delivered over telecom or data network to a range of external business areas. Sourcing channels are the genesis that are considered handy, tried and tested sources used for talent acquisition for an organization.

\section{Objective of the study:-}

Innovations in technology; social and mobile in particular, have empowered the paradigm shift in the way to acquire talent. As a result, many traditional practices in the domain of human resources have come under scrutiny as business leaders look for more effective ways for talent acquisition. The main purpose of this paper is to study the perception of employee and employer about the top strategic goals of an organization as well as the methods used for assessing the candidature in talent acquisition. The strategic goals considered for the research purpose are as follows

- To attract more talent

- To hire better talent

- To improve candidate experience

- To strengthen employer brand

- $\quad$ To reduce cost per hire

- $\quad$ To reduce time to hire

- To improve new hire retention

- To improve time to proficiency

Whereas the methods used for assessing the candidate in talent acquisition process is as follows

- Screening questions included in the application process

- Phone screening with recruiter

- Video screening/interviewing

- Traditional one-on-one, in-office interviews

- Social networks

- Behavioral assessments

- Skills and competencies testing

- Third-party assessment tools

\section{Research Methodology:-}

For this context of research the researcher has taken two tiered approach to gather data and researching key practices in talent acquisition among organizations of all sites. Researcher has broken down the methodology as described below

1. Empirical Research: Researcher conducted online survey between January 2015 to April 2015, researcher had circulated questionnaire to 232 employees and 56 employers/recruiters of different IT industries in Nagpur.

2. Referred Research: Here researcher reviewed, studied and analyzed empirically based strategic research from various reports related to IT organizations dealt on the same issue.

Researcher has used spearman's correlation test and then has validated the score for significance with the help of TTest

Hypothesis:-

On the basis of above discussion researcher concluded on the following hypothesis

Hypothesis-1 
H0: Employer and employee have significantly different perceptions about the top three strategic goals for TA used by organization

\section{Hypothesis-2}

H0: Employer and employee have significantly different perceptions about the methods used to assess the candidate in talent acquisition process

\section{Analysis and Interpretation:-}

Hypothesis-1:-

Sample observations (Responses are in percentages)

\begin{tabular}{|l|l|l|}
\hline Strategic goal for Talent acquisition & Employer & Employee \\
\hline To attract more talent & 19.64 & 40.95 \\
\hline To hire better talent & 41.07 & 38.79 \\
\hline To improve candidate experience & 37.50 & 38.79 \\
\hline To strengthen employer brand & 44.64 & 36.64 \\
\hline To reduce cost per hire & 53.57 & 40.95 \\
\hline To reduce time to hire & 50.00 & 41.81 \\
\hline To improve new hire retention & 25.00 & 34.91 \\
\hline To improve time to proficiency & 21.43 & 36.64 \\
\hline
\end{tabular}

Table 1:- Employer and employee responses on top 3 strategic goals for talent acquisition

Spearman's Rank Correlation Coefficient

\begin{tabular}{|l|l|l|l|l|}
\hline \multicolumn{2}{|l|}{ Correlations } & Empr_res & Empe_res \\
\hline \multirow{3}{*}{ Spearman's rho } & \multirow{2}{*}{ Empr_res } & Correlation Coefficient & 1.000 & .388 \\
\cline { 3 - 5 } & & Sig. (2-tailed) &. & .342 \\
\cline { 3 - 5 } & $\mathrm{N}$ & 8 & 8 \\
\cline { 2 - 5 } & \multirow{2}{*}{ Empe_res } & Correlation Coefficient & .388 & 1.000 \\
\cline { 3 - 5 } & & Sig. (2-tailed) & 8 & 8 \\
\cline { 3 - 5 } & $\mathrm{N}$ & 842 & 8 \\
\hline
\end{tabular}

Table 2:- Spearman's rho on top 3 goals of organization employee and employers perspective

From the above table researcher can conclude that, the spearman's rank correlation coefficient is $r=0.342$, which means there exist a positive correlation between employer and employees perception about the organizations top strategic goals for talent acquisition.

Researcher further applied T Test to check whether the results can be generalized for the entire population, for the same researcher has used the hypothesis for population as below

H0: $\rho=0$ (The correlation is not significant)

H1: $\rho \neq 0$ (The correlation is significant)

The results comes out to be $t=1.031$, for two tailed test and significance level $=0.05$ the lower curve value and upper curve value comes out to be -2.447 and 2.447 , since the calculated $t$ value (1.031) lies in the non-rejection area, researcher can conclude that there is sufficient evidence to reject null hypothesis hence we can now firmly say that the correlation so observed between employee and employer perception about the organizations strategic goals for talent acquisition are not significant.

\section{Hypothesis-2}

Sample observations (Responses are in percentages)

\begin{tabular}{|l|l|l|}
\hline Method Used to assess candidate in TA process & Employer & Employee \\
\hline Screening questions included in the application process & 59.48276 & 62.5 \\
\hline Phone screening with recruiter & 58.62069 & 51.78571 \\
\hline Video screening/interviewing & 57.32759 & 58.92857 \\
\hline Traditional one-on-one, in-office interviews & 49.56897 & 51.78571 \\
\hline Social networks & 59.05172 & 55.35714 \\
\hline
\end{tabular}




\begin{tabular}{|l|l|l|}
\hline Behavioral assessments & 56.03448 & 57.14286 \\
\hline Skills and competencies testing & 59.05172 & 48.21429 \\
\hline Third-party assessment tools & 48.27586 & 46.42857 \\
\hline
\end{tabular}

Table 3:- Employer and employee responses on perceptions about the methods used to assess the candidate in talent acquisition process

Spearman's Rank Correlation Coefficient

\begin{tabular}{|c|c|c|c|c|}
\hline \multicolumn{5}{|l|}{ Correlations } \\
\hline & & & Employee & Employer \\
\hline \multirow{6}{*}{ Spearman's rho } & \multirow{3}{*}{ Employee } & Correlation Coefficient & 1.000 & .458 \\
\hline & & Sig. (2-tailed) & . & .254 \\
\hline & & $\mathrm{N}$ & 8 & 8 \\
\hline & \multirow{3}{*}{ Employer } & Correlation Coefficient & .458 & 1.000 \\
\hline & & Sig. (2-tailed) & .254 & . \\
\hline & & $\mathrm{N}$ & 8 & 8 \\
\hline
\end{tabular}

Table 4:- Spearman's Rho on perceptions about the methods used to assess the candidate in talent acquisition process.

From the above table researcher can conclude that, the spearman's rank correlation coefficient is $r=0.458$, which means there exist a positive correlation between employer and employees perception about the methods used to assess the candidate in talent acquisition process.

Researcher further applied T Test to check whether the results can be generalized for the entire population, for the same researcher has used the hypothesis for population as below.

H0: $\rho=0$ (The correlation is not significant)

H1: $\rho \neq 0$ (The correlation is significant)

The results comes out to be $t=1.26$, for two tailed test and significance level $=0.05$ the lower curve value and upper curve value comes out to be -2.447 and 2.447 , since the calculated t value (1.26) lies in the non-rejection area, researcher can conclude that there is sufficient evidence to reject null hypothesis hence we can now firmly say that the correlation so observed between employee and employer perception about the methods used to assess the candidate in talent acquisition process is significant.

\section{Conclusion:-}

The data is evident from the fact that though there exist a strong positive correlation among employee and employer's perception they are not significant which implies that the organization shall shift the paradigm towards setting new strategic goals to attract, recruit and retain best talent. Further the methods used to assess the candidate in talent acquisition process have same significant perception among employee and employer; here organizations have not to worry more as what they are using are highly acceptable by the employees.

\section{References:-}

1. "An Introduction to LEED." US Green Building Council. US Green Building Council, n.d. Web. 16 Mar 2010. <http://www.usgbc.org/DisplayPage.aspx?CategoryID=19>.

2. BNET Basics, Where Your Customers Are: How Facebook, Twitter and Others Breakdown by Age. http://www.bnet.com/2403-13237_23-366331.html

3. Doug Berg, Social Recruiting: What's Your Strategy?, Recruiting Trends,

4. http://www.recruitingtrends.com/article/ART637037?C (2009)

5. Gautam Godhwani, Search Engine Optimization for Jobs, Recruiting Trends,

6. http://www.recruitingtrends.com/?p=1034 (February 15, 2010)

7. IBM (2008) 'Integrated Talent Management: Part 1 - Understanding the opportunities for success', IBM Global Business Services, IBM Institute for Business Values

8. Josh Bersin, Enterprise Learning and Talent Management Predictions 2010, Bersin \& Associates Research Report (December 2009) 
9. Julia Christensen Hughes, Evelina Rog (2008) 'Talent Management: A strategy for improving employment recruitment, retention and engagement within hospitality organizations', International Journal of Contemporary Hospitality Management, 20 (7) 743 - 757

10. Madeline Laurano, The Power of Referrals: Next Generation Recruitment, http://www.bersin.com/blog (March 12, 2009)

11. Talent Management, Adopt Eight Resolutions to Engage Employees in 2010,

12. http://www.talentmgt.com/industry_news/2009/December/5087/index.php (December 1, 2009)

13. Roberts, G. 2005. Recruitment \& Selection. 2nd ed. Chartered Institute of Personnel and Development (CIPD). London.

14. Sloan Center of Aging \& Work at Boston College, Despite Warnings, U.S. Companies Remain Unprepared for Baby Boomer Exodus, (November 16, 2009)

15. Volpe, L. \& Tucker, J. 2004. Third-party recruiting. Employment Relations Today, 31, 1, pp

16. http://www.ere.net/2014/01/27/these-strategic-goals-can-help-to-focus-your-recruiting-function/ 